\title{
Preparation of hydrogen chloride in hydrogen standard gas mixtures for hydrogen purity requirements
}

\author{
Andrés Rojo ${ }^{1, *}$, Enrique Santamaría ${ }^{1}$ \\ ${ }^{1}$ Centro Español de Metrología, Reference Gas Laboratory, 28760 Tres Cantos, Madrid, Spain
}

\begin{abstract}
The hydrogen gas dispensed as fuel in refuelling stations for Fuel Cell Electric Vehicles (FCEV) should meet with purity requirements according to the actual normative. In this report we approach the preparation of hydrogen chloride/hydrogen $\left(\mathrm{HCl} / \mathrm{H}_{2}\right)$ standard gas mixtures, required to support the purity analysis of hydrogen fuel. The preparation of these mixtures was perform according to the gravimetric method, using dilution steps to reach the concentration level of 10 $\mu \mathrm{mol} / \mathrm{mol}$ as the lowest. The mixtures were prepared in $5 \mathrm{~L}$ aluminium alloy cylinders with no internal treatment.
\end{abstract}

\section{Introduction}

The use of hydrogen as fuel for Fuel Cell Electric Vehicles (FCEV) is one of the newly rising applications within automotive area. With water as only exhaust product, it makes this kind of transport one of the cleanest of the sector, and if the production process is from renewable sources, then it is possible to obtain a beneficial circular path to decarbonising the automotive industry. This is one of the premise in the European Directive 2014/94/EU [1] where it is stated the need for the deployment of an alternative fuels infrastructure. In line with this premise, and as part of Horizon 2020 [2], the European Metrology Programme for Innovation and Research (EMPIR) [3] has supported two projects related with hydrogen fuel in the last few years: 15NRM03-Hydrogen and 16ENG01-MetroHyVe $[4,5]$. Both projects show the necessity of evaluate the purity of the hydrogen used as fuel to ensure the proper lifespan of the fuel cell. As it is also set out in the European Directive, this hydrogen dispensed as fuel for FCEV shall meet the quality requirements from the ISO 14687-2:2012 [6], that means, that analytical tests shall be performed for the 13 compounds listed on the Standard (Fig. 1). Because of the reactivity of some of these species and the low level of concentration required, the analysis of these parameters seems to be challenging for a large number of laboratories these days, so it will be necessary to develop new analytical methods and reference materials which could assess the purity requirements of the fuel dispensed at the hydrogen refuelling stations (HRS).

\footnotetext{
*Corresponding author: arojo@cem.es
} 
The Reference Gas Laboratory of the National Metrology Institute of Spain (CEM), as part of the work carried out within the two EMPIR projects, has undertaken the preparation of primary reference gas mixtures (PRGM) of hydrogen chloride with hydrogen as balance gas $\left(\mathrm{HCl} / \mathrm{H}_{2}\right)$. The preparation of the mixtures is made by gravimetric method according to ISO 6142:2015 [7], weighing the previously calculated mass of each compound of the mixture after adding it into a gas cylinder. These PRGM will help to develop and validate new analytical methods and provide a traceable reference value to the hydrogen quality testing laboratories.

\begin{tabular}{|c|c|}
\hline $\begin{array}{c}\text { ISO } 14687-2 \\
\text { Quality Requirements }\end{array}$ & $\begin{array}{c}\text { Max. } \\
\text { Concentration } \\
(\mu \mathrm{mol} / \mathrm{mol})\end{array}$ \\
\hline water $\left(\mathrm{H}_{2} \mathrm{O}\right)$ & 5 \\
\hline Total hydrocarbons (Methane basis) & 2 \\
\hline Oxygen $\left(\mathrm{O}_{2}\right)$ & 5 \\
\hline Helium (He) & 300 \\
\hline Nitrogen $\left(\mathrm{N}_{2}\right)$ & 100 \\
\hline Argon (Ar) & 100 \\
\hline Carbon dioxide $\left(\mathrm{CO}_{2}\right)$ & 2 \\
\hline Carbon monoxide (CO) & 0,2 \\
\hline $\begin{array}{l}\text { Total sulphur compounds } \\
\left(\mathrm{H}_{2} \mathrm{~S}, \mathrm{SO}_{2} \ldots\right)\end{array}$ & 0,004 \\
\hline Formaldehyde ( $\mathrm{HCHO})$ & 0,01 \\
\hline Formic Acid ( $\mathrm{HCOOH})$ & 0,2 \\
\hline Ammonia $\left(\mathrm{NH}_{3}\right)$ & 0,1 \\
\hline $\begin{array}{l}\text { Total halogenated compounds (Cl; } \\
\mathrm{Br}, \mathrm{F}-\text { ) }\end{array}$ & 0,05 \\
\hline
\end{tabular}

Fig. 1. Maximum concentration of individual contaminants in hydrogen fuel for PEM (Proton Exchange Membrane) fuel cells in road vehicles according to ISO 146872-2:2012.

\section{Experimental}

A multi-step dilution process was perform to prepare several batches of mixtures ranging from $\sim 4 \%$ to $10 \mu \mathrm{mol} / \mathrm{mol} \mathrm{HCl}$ in $\mathrm{H}_{2}$, starting from pure hydrogen chloride (3.0 quality, Air Products) and pure hydrogen (5.7 quality BIP®, Air Products). 5 L aluminium alloy cylinders (with no internal wall treatment) were used to prepare the mixtures.

An improvement in the former facilities of the filling gas laboratory was necessary to fit with safety requirements. First, both $\mathrm{HCl}$ and $\mathrm{H}_{2}$ pure gas cylinders were located outdoor, in a gas shed, where also a pure nitrogen gas cylinder (5.7 quality BIP $\AA$, Air Products) was connected to use as purge gas. This action avoided the purchase of a safety gas cabinet, which was the first idea when the project was on its design stage, with corresponding savings in time and cost. Secondly, a new filling station panel was installed in the filling gas laboratory for only $\mathrm{HCl}$ use. A modification of the former manifold of the gas shed was also performed to allow purging with dry nitrogen after an empty pure $\mathrm{HCl}$ cylinder is replaced and similar design was proposed in the new filling station panel so it is possible to purge the lines with nitrogen before filling with $\mathrm{HCl}$. 
The analytical measurements were performed with an Agilent 3000A micro gas chromatograph with thermal conductivity detector ( $\mu \mathrm{GC}-\mathrm{TCD})$, equipped with a PLOT-U $(3 \mathrm{~m} \times 0.30 \mathrm{~mm} \times 30 \mu \mathrm{m})$ pre-column and a Molsieve 5A column $(10 \mathrm{~m} \times 0.30 \mathrm{~mm} \times 30$ $\mu \mathrm{m}$ ), and an Agilent 6890 GC gas chromatograph with a PDHID detector (Pulsed Discharge Helium Ionization Detector) from VICI-VALCO and a capillary column HPMOLESIEVE 5A (30 $\mathrm{m} \times 0.53 \mathrm{~mm} \times 50 \mu \mathrm{m})$.

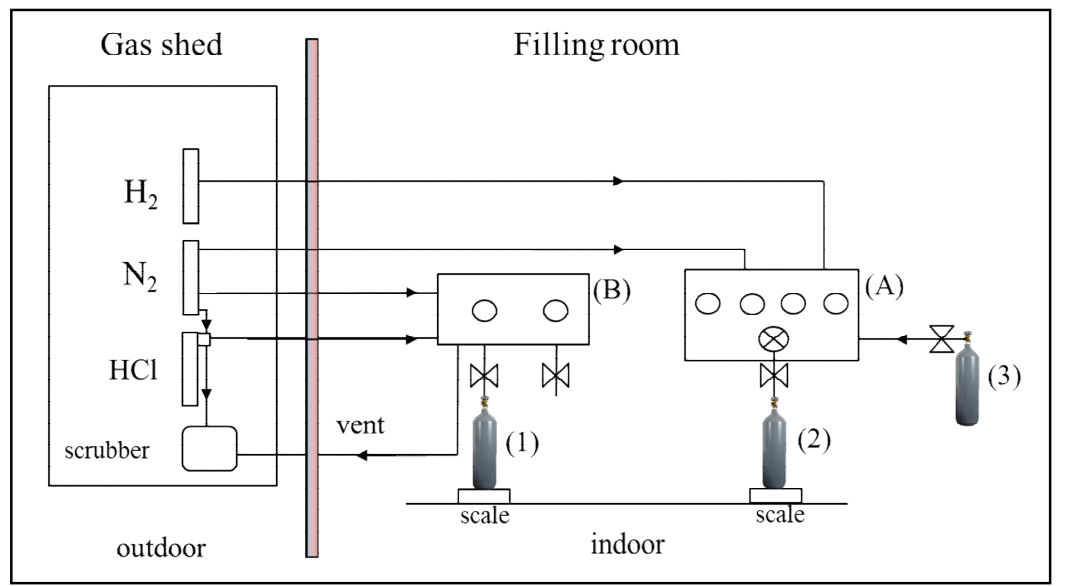

Fig. 2. Schematic of the $\mathrm{HCl}$ filling system. (A) Filling control panel currently installed at laboratory used to prepare the mixtures from dilution steps. (B) Filling control panel newly installed to use exclusively with pure $\mathrm{HCl}$. This panel allows purging with nitrogen and vent through the scrubber.

\subsection{Filling process}

\subsubsection{Purging}

After connecting the pure $\mathrm{HCl}$ cylinder for first time, the pipe lines of the manifold are purged up to eight times, first with nitrogen and after with $\mathrm{HCl}$. The same procedure is carried out to purge the lines of the filling control panel after a cylinder is connected. During purging the gas is vented to the scrubber, which is filled with tapped water where the vented $\mathrm{HCl}$ is absorbed.

\subsubsection{Filling}

An evacuated cylinder is connected to the new filling control panel and then the lines are purged with nitrogen and $\mathrm{HCl}$ as stated above. Previously the cylinder has been weighed and the quantity of gas which has to be introduced to reach the target concentration of the mixture has been calculated. A scale with $0.1 \mathrm{~g}$ resolution (SR16001 Mettler Toledo) is used for weighing at first and then a mass comparator (PR10003 Mettler Toledo) with $0.001 \mathrm{~g}$ resolution is used to check the real mass of gas which has been introduced [7]. When the preparation of a diluted mixture is required, the filling process is carried out using the old control panel following the same process. 


\section{Results and discussion}

The first analysis were performed with the $\mu$ GC-TCD because of its high versatility when changing the carrier gas. As it was shown in previous work related with hydrogen purity the $\mu \mathrm{GC}-\mathrm{TCD}$ would be able to detect the $\mathrm{HCl}$ at concentration level of $50 \mu \mathrm{mol} / \mathrm{mol}$ [8], but it was no possible for us to determine the $\mathrm{HCl}$, not even in much more concentrated mixtures. Our work continued testing the mixtures in a 6890GC with the PDHID detector, although there were not very positive signs [8], the experience gained during the last years and the good sensitivity always got with this detector made us think that it could work. But, after several analysis of a $500 \mu \mathrm{mol} / \mathrm{mol}$ of $\mathrm{HCl}$, it was still not possible to see the $\mathrm{HCl}$ peak.

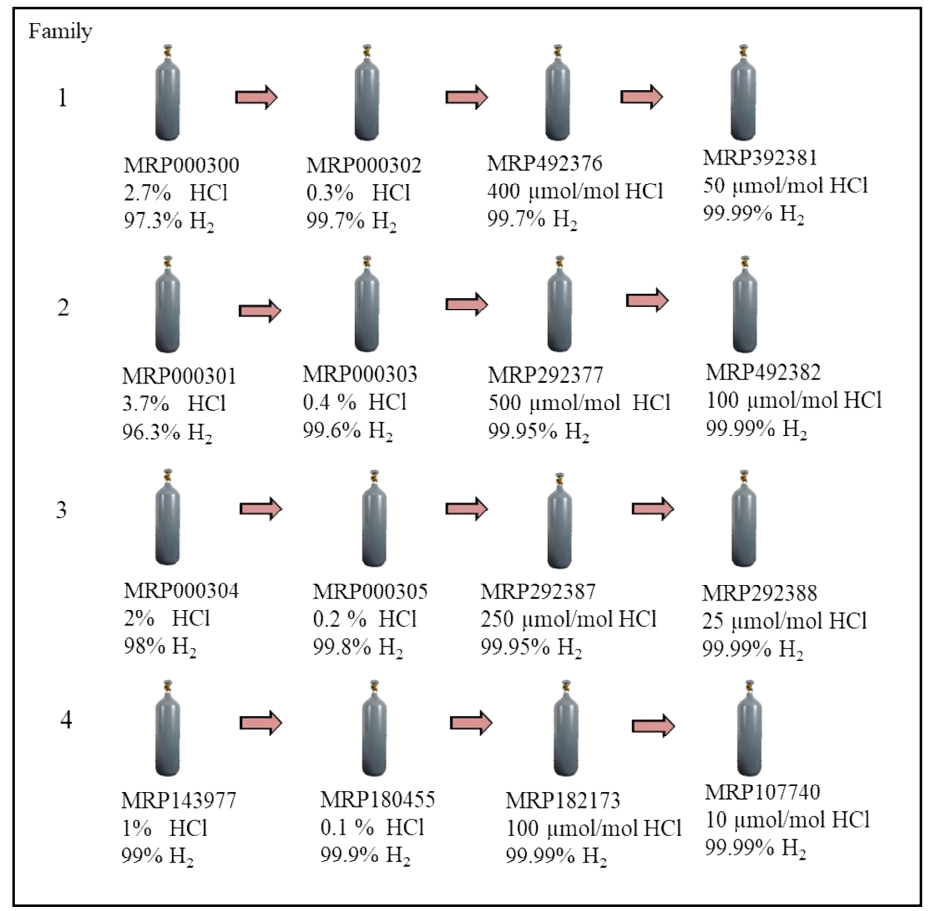

Fig. 3. Schematic of the first four families of mixtures prepared using dilution steps (the concentration shown is the nominal value).

Within the work of the 15NRM03-Hydrogen project a mixture with a nominal concentration of $50 \mu \mathrm{mol} / \mathrm{mol}$ of $\mathrm{HCl}$ in $\mathrm{H}_{2}$ was sent to a project partner. The mixture was analysed using CRDS technique (Cavity Ring Down Spectroscopy) resulting 45.5 $\mu \mathrm{mol} / \mathrm{mol}$, that was fairly consistent with the gravimetric value $55.2 \mu \mathrm{mol} / \mathrm{mol}$ [9]. The discrepancy could be evidenced because of the lack of stability of these mixtures that leads to recommend the use of cylinders with an adequate internal wall treatment $[10,11]$.

\section{Conclusion and further work}

For the preparation of $\mathrm{HCl}$ standard gas mixtures, it has been necessary to modify the current facilities of the filling gas laboratory to improve the purging process and furthermore comply with safety requirements. The purge of the lines before each filling 
with dry nitrogen is one of the important routines of the process to avoid the formation of hydrochloric acid because of the $\mathrm{HCl}$ itself and traces of water inside the tubes. The preparation of the mixtures was then carried out by gravimetric method throughout three dilution steps to reach a low ppm level (Fig. 3), achieved a high number of mixtures without any technical issue. On the downside, the available analytical techniques at the laboratory proved to be inadequate and did not allow us to certify the gravimetric value so far. Although the consistent result on the travel mixture obtained from other project partner using CRDS technique could give us some hopeful signs. In the continuation of this work it will be important to develop an analytical method able to determine $\mathrm{HCl}$ in hydrogen according with the normative stated before. A proper analytical technique will also enable us to study the stability of the mixtures and the effect of using internal coated cylinders (currently planned to be purchased by CEM), against regular cylinders, that seems to be another critical aspect according with the literature.

\section{Acknowledgement}

This project (16ENG01-Metrohyve) has received funding from the EMPIR programme co-financed by the Participating States and from the European Union's Horizon 2020 research and innovation programme.

\section{References}

1. Directive 2014/94/EU of the European Parliament and of the Council of 22 October 2014 on the deployment of alternative fuels infrastructure.

2. Horizon 2020 : https://ec.europa.eu/programmes/horizon2020

3. The European Metrology Programme for Innovation and Research (EMPIR). https://www.euramet.org/research-innovation/research-empir/

4. 15NRM03-Hydrogen: Metrology for sustainable hydrogen energy applications. http://projects.lne.eu/jrp-hydrogen/

5. 16ENG01-MetroHyve: Metrology for hydrogen vehicles. http://www.metrohyve.eu

6. ISO 14687-2:2012 Hydrogen fuel — Product specification - Part 2: Proton exchange membrane (PEM) fuel cell applications for road vehicles

7. ISO 6142:2015 Gas analysis - Preparation of calibration gas mixtures - Part 1: Gravimetric method for Class I mixtures

8. Deliverable D2.3 - Intermediate report on the performance of existing and new hydrogen purity analysis methods. HyCoRA. http://hycora.eu

9. Report A2.2.2 - Validate a speciation method for the measurement of halogenated species in hydrogen. 15NRM03-HYDROGEN. http://projects.lne.eu/jrp-hydrogen/

10. J. T. van Wijk, G. Nieuwenkamp, T. L. Hafkenscheid, Fresenius J. Anal. Chem. 370, 200-202 (2001)

11. A2.3.1 MetroHyVe Report - Review passivation treatments. 16ENG01-MetroHyve. http://www.metrohyve.eu/ 